of: Sobi employee and holder of Sobi shares, Speakers bureau: Sobi employee and holder of Sobi shares, Paid instructor for: Sobi employee and holder of Sobi shares, Consultant of: Sobi employee and holder of Sobi shares, Grant/ research support from: Sobi employee and holder of Sobi shares, Employee of: Sobi employee and holder of Sobi shares, Francesca Bagnasco: None declared, Nicolino Ruperto: None declared, Marco Gattorno: None declared DOI: 10.1136/annrheumdis-2021-eular.3995

\section{POS1331 LONG-TERM OUTCOME IN CHILDREN WITH JUVENILE DERMATOMYOSITIS FROM SOUTHERN INDIA}

P. R. Chickermane ${ }^{1}$, M. Kuriakose2, A. Tiwari2, A. Shahul2, S. Balan2. ${ }^{1}$ Amrita Institute of Medical Sciences, Clinical Immunology and Rheumatology, Kochi, India; ${ }^{1}$ Amrita Institute of Medical Sciences, Clinical Immunology and Rheumatology, Kochi, India

Background: There is paucity of data regarding long-term outcome and cumulative damage in children with juvenile dermatomyositis (JDM) from the Indian subcontinent.

Objectives: To assess the long-term outcome and cumulative damage in children with JDM receiving treatment at a tertiary hospital in southern India.

Methods: Retrospective review of records and cross-sectional assessment of outcome and damage in 29 patients with JDM at a tertiary hospital in Kochi, India. The disease course was categorized as monocyclic, polycyclic and chronic progressive. Cumulative damage was assessed using the IMACS myositis damage index (MDI)

Results: Twenty-nine patients (male-16) diagnosed with definite or probable juvenile dermatomyositis based on the Bohan and Peter criteria and having a minimum follow-up period of 3 years each were enrolled. Of these, 20 children were diagnosed and initiated on treatment at our institute (inceptional) and 9 were diagnosed elsewhere and referred to our centre for further management (non-inceptional). The mean age at disease onset was $7.01 \pm 3.34$ years (range 1.0 to 13.5 years). The median interval from onset to diagnosis was 3 months (range- 3 weeks to 8.75 years). Delayed diagnosis defined as interval from onset to diagnosis exceeding 6 months was noted in case of 8 children. Among patients in the non-inceptional group, six were considered to have not received standard of care treatment prior to referral to our centre. Standard of care treatment was defined as initiation of a treatment regimen comprising of a combination of glucocorticoids with an immunosuppressive agent within 4 weeks of diagnosis. A total of 11 children had a delayed diagnosis and/or had not received standard of care treatment prior to referral.

At our centre, all patients received oral steroids and subcutaneous methotrexate as standard therapy. Pulse steroids were used to induce remission in 12 patients and as a rescue for relapses in 2 patients. Intravenous immunoglobulin was used in 10 children with severe myositis, oropharyngeal weakness, refractory cutaneous disease including calcinosis and concomitant infection, where affordable with good results. Hydroxychloroquine was added in 15 patients with dominant cutaneous manifestations. Mycophenolate mofetil, azathioprine and tacrolimus were used in patients refractory or intolerant to methotrexate. Cyclophosphamide and rituximab were used in 4 patients each with refractory disease and extra-muscular manifestations such as interstitial lung disease. Seven patients with refractory calcinosis received pamidronate infusions.

\section{Frequency of specific damage items using the MDI}

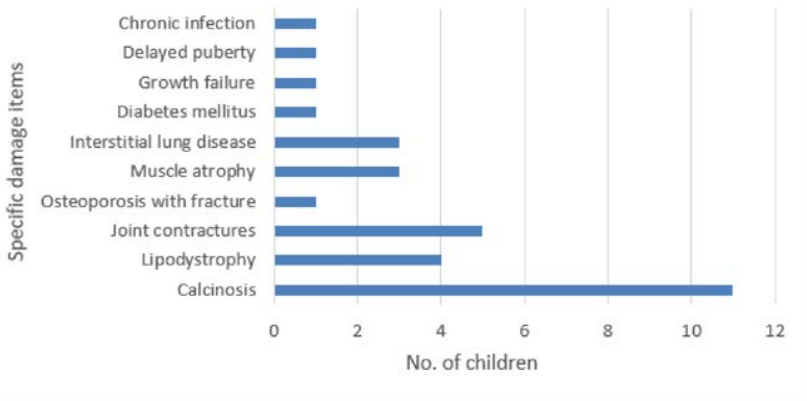

The total follow-up duration was 121.06 patient-years. A monocyclic course was observed in $11 / 29(37.9 \%)$, chronic progressive course in 16/29 (55.2\%) and polycyclic course in $2 / 29(6.9 \%)$. Nearly half of the patients $(14 / 29)$ had damage in at least one organ using the MDI (MDI $\geq 1)$. $38 \%$ of the patients (11/29) had at least one sign of cutaneous damage, the most common being calcinosis $(n=11)$ and lipodystrophy $(n=4)$. This was followed by skeletal damage $(n=6$, joint contractures-5, osteoporosis with fracture-1), muscle and pulmonary (pulmonary fibrosis) damage in 3 patients each, endocrine damage in 2 patients (diabetes mellitus-1, growth failure and delayed development of secondary sexual characteristics-1) and chronic infection in one patient. All patients with damage in a least one organ had a chronic progressive course, indicating damage accrual. Delayed diagnosis and lack of standard of care treatment prior to referral (i.e. longer duration of untreated/ sub-optimally treated disease) were associated with an increased risk of cumulative damage $(p<0.05)$.

Conclusion: Nearly half of the patients had damage in at least one organ using the MDI. Cutaneous damage was the most common, followed by skeletal, muscle pulmonary and endocrine damage. Longer duration of untreated/ sub-optimally treated disease significantly increases the risk of cumulative damage, highlighting the need for an early diagnosis and referral to pediatric rheumatology services.

Disclosure of Interests: None declared

DOI: 10.1136/annrheumdis-2021-eular.4010

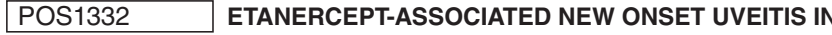 PATIENTS WITH JUVENILE IDIOPATHIC ARTHRITIS UNDER BIOLOGICAL THERAPY: SINGLE CENTER EXPERIENCE}

I. Nikishina ${ }^{1}$, S. Arsenyeva ${ }^{1}$, M. Kaleda ${ }^{1}$, O. Kostareva ${ }^{1}$, A. Shapovalenko ${ }^{1}$, E. Denisova ${ }^{2}$, A. Panova ${ }^{1,2}$. ${ }^{1}$ V.A. Nasonova Research Institute of Rheumatology, Pediatric Department, Moscow, Russian Federation; ${ }^{2}$ Helmgoltz Moscow Research Institute of Eye Diseases, Pediatric Department, Moscow, Russian Federation

Background: Biological agents (BA), especially TNF inhibitors, are high efficacy options for current therapy for patients (pts) with juvenile idiopathic arthritis (JIA). They are successfully used not only for the arthritis but also for JIA-associated uveitis, however, development of uveitis de novo in pts treated with BA is a well-established paradoxical phenomenon.

Objectives: to evaluate the frequency of new onset (no-) uveitis, occurring under BA therapy in JIA pts, to establish clinical features, which may be associated with development of such effects.

Methods: retrospective cohort study involved all JIA pts (1136) who were treated with BA in our clinic from 2004 to 2020 . All cases of no-uveitis were collected for the describing of their clinical features in disease onset and course, activity level JIA category, exposure to Methotrexate (MTX) and BA, presence of ANA, HLA B27. Results: among of 1136 pts treated with different BA we identified 36 (3.3\%) pts (19 female/17 male) with no-uveitis under BA. Mostly during etanercept (ETA) therapy (34 cases from 488 ETA courses, 7\%), 1/166 - in abatacept (ABA) and 1/372 in adalimumab (ADA). 30 pts ( $83 \%)$ with no-uveitis developed it on the $1^{\text {st }}$ line of BA treatment (29 ETA vs 1 ADA). 4pts (11\%) developed no-uveitis on $2^{\text {nd }}$ line (3 ETA vs $1 \mathrm{ABA}) .2$ pts $(6 \%)$ on third line (all ETA, both pts had also psoriasis). There are no cases of no-uveitis under other BA. Frequency of no-uveitis was much higher in ETA group. ETA exposure was $26.8 \pm 28.8$ months $(\mathrm{mo})$. It means there are no "safe" period of therapy from paradoxical phenomenon of no-uveitis. JIA subtypes were as follows: RF-neg polyarthritis $9(25 \%)$, persistent oligoarthritis $3(8 \%)$, extended oligoarthritis 21 (59\%), enthesitis-related arthritis (ERA) - 3 (8\%). Average age at JIA onset was $4.6 \pm 3.9 \mathrm{yrs}$. 20/36 patients had high laboratory activity (CRP $54 \pm 23 \mathrm{mg} / \mathrm{l}$; ESR $41 \pm 19 \mathrm{~mm} / \mathrm{h}$ ) and severe arthritis before BA initiation. However most of pts (25/36) achieved $90-100 \%$ ACRpedi-response by the uveitis development. $23 / 36$ pts were ANA-positive, $17 / 36$ pts had HLAB27, including 7 pts who had the both features. Uveitis was occurred earlier in ANA plus HLAB27 positive pts (mean exposure - $15.3 \mathrm{mo}$ ) than in only ANA-positive or HLAB27-positive pts (27.7 mo and 27.6 mo accordingly). $29 / 36$ (81\%) of pts received methotrexate (MTX) in mean dosage $11.5 \mathrm{mg} / \mathrm{m}^{2} /$ week. There are no differences in time of uveitis development depending of MTX. In all cases of no-uveitis BA was switched.

Conclusion: Our study suggested that new onset of uveitis is rare adverse event during BA therapy in JIA. Uveitis can develop despite the excellent effect of therapy on joint manifestation. The most typical development of no-uveitis is under ETA therapy, especially in the predisposed cases (certain variants of JIA, ANF positivity, HLAB27 presence) and in patients with very high disease activity at the time of the start of biological therapy.

Disclosure of Interests: Irina Nikishina Speakers bureau: Novartis, MSD, Pfizer Abbvie, Hofman la Roche, Svetlana Arsenyeva: None declared, Maria Kaleda Speakers bureau: Novartis, Roche, MSD, Olga Kostareva: None declared Anna Shapovalenko: None declared, Ekaterina Denisova: None declared, Anna Panova: None declared

DOI: 10.1136/annrheumdis-2021-eular.4135

\section{POS1333 \\ ANKLE ARTHRITIS IN JUVENILE IDIOPATHIC ARTHRITIS: DON'T MISS TENOSYNOVITIS. CLINICAL AND SONOGRAPHIC FEATURES OF ANKLE} TENOSYNOVITIS IN JIA

S. Pastore ${ }^{1}$, S. Della Paolera ${ }^{1}$, A. Zabotti ${ }^{2,3}$, A. Tommasini ${ }^{1,4}$, A. Taddio ${ }^{1,4}$.

${ }^{1}$ IRCCS Burlo Garofolo, Pediatric Department, Trieste, Italy; ${ }^{2}$ Azienda Sanitaria 